\title{
Pyranine-Modified Amphiphilic Polymer Conetworks as Fluorescent Ratiometric pH Sensors
}

Sebastian Ulrich, Alina Osypova, Guido Panzarasa, René M. Rossi, Nico Bruns*, and Luciano F. Boesel*

Dr. S. Ulrich, Dr. A. Osypova, Dr. G. Panzarasa, Prof. R. M. Rossi, Dr. L. F.

Empa, Swiss Federal Laboratories for Materials Science and Technology,

Laboratory for Biomimetic Membranes and Textiles,

Lerchenfeldstrasse 5, 9014 St. Gallen, Switzerland

E-mail: luciano.boesel@empa.ch

Prof. N. Bruns

Department of Pure and Applied Chemistry

University of Strathclyde

Thomas Graham Building, 295 Cathedral Street, Glasgow G1 1XL, United Kingdom

E-mail: nico.bruns@strath.ac.uk

Dr. S. Ulrich, Prof. N. Bruns,

Adolphe Merkle Institute

University of Fribourg

Chemin des Verdiers 4, 1700 Fribourg, Switzerland

Dr. G. Panzarasa

Current address:

Laboratory for Soft and Living Materials

Department of Materials

ETH Zürich, Vladimir-Prelog-Weg 5, Zürich 8093,

Keywords: pyranine, optical pH sensor, fluorescent dye, amphiphilic polymer conetwork, nanophase separation

This is the peer reviewed version of the following article:

Ulrich, S., Osypova, A., Panzarasa, G., Rossi, R. M., Bruns, N., Boesel, L. F., PyranineModified Amphiphilic Polymer Conetworks as Fluorescent Ratiometric pH Sensors.

Macromol. Rapid Commun. 2019, 1900360.,

which has been published in final form at https://doi.org/10.1002/marc.201900360. This article may be used for non-commercial purposes in accordance with Wiley Terms and Conditions for Use of Self-Archived Versions. 
The fluorescent dye 8-hydroxypyrene-1,3,6-trisulfonate (pyranine) combines high photostability with ratiometric $\mathrm{pH}$ detection in the physiological range, making it a prime candidate for optical sensors in biomedical applications, such as pH-based chronic wound monitoring. However, pyranine's high water solubility and the difficulty of covalent attachment pose severe limitations in terms of leaching from sensor matrices. Herein, pyranine-modified nanophase-separated amphiphilic polymer conetworks (APCNs) are reported as fluorescent ratiometric $\mathrm{pH}$ sensors. The thin, free-standing APCN membranes composed of one hydrophilic and one hydrophobic polymer provide an optically transparent, flexible and stable ideal matrix that enables contact between dye and aqueous environment. An active ester-based conjugation approach results in a highly homogeneous and stable pyranine modification of the APCN's hydrophilic phase. This concept effectively solves the leaching challenge for pyranine without compromising its functionality, which is demonstrated by ratiometric $\mathrm{pH}$ detection in the range of $\mathrm{pH} 5$ to 9. 
A large number of different fluorescent dyes are employed for sensor applications in the life sciences. ${ }^{[1-3]}$ Yet few of them display a set of properties as favorable as that of 8hydroxypyrene-1,3,6-trisulfonate (pyranine or HPTS), a water-soluble, highly photostable and non-toxic bright yellow dye with an intense, vibrant fluorescence. ${ }^{[4-5]}$ Another outstanding feature of pyranine is its capability of fluorescence-based ratiometric $\mathrm{pH}$ detection. Typically, ratiometric $\mathrm{pH}$ detection requires the combination of one $\mathrm{pH}$-sensitive and one $\mathrm{pH}$-insensitive fluorescent dye. ${ }^{[3]}$ Pyranine, in contrast, allows ratiometric detection of $\mathrm{pH}$ from the comparison of one emission intensity at two different excitation wavelengths $(406 / 460 \mathrm{~nm}){ }^{[6]}$ This dual excitation-single emission property minimizes the impact of variations in fluorophore concentration, photobleaching and instrumentation. The $\mathrm{pH}$ sensitivity of pyranine arises from its phenol group with a $\mathrm{pK}_{\mathrm{a}}$ of 7.3 that allows the determination of $\mathrm{pH}$ values ranging from $\sim 5$ to $\sim 9$, adequate for biologically or biomedically-oriented applications. ${ }^{[7-8]}$ Accordingly, pyranine has been employed to measure intracellular $\mathrm{pH},{ }^{[2,9-10]}$ track protein structural transitions, ${ }^{[9-12]}$ for metal ion-sensing, ${ }^{[13]}$ and for the development of environmental sensors. ${ }^{[14-16]}$ The monitoring of chronic wounds via $\mathrm{pH}$-sensitive wound pads is a relevant application, in particular, due to the similar relevant $\mathrm{pH}$ range. ${ }^{[17-18]}$ The low price of pyranine compared to other fluorescent dyes is especially attractive for commercial applications, even allowing its use in fluorescent text markers. However, due to the difficulty of covalent conjugation, with few exceptions, ${ }^{[19-22]}$ most pyranine sensors are based on noncovalent integration. ${ }^{[15,23-26]}$ Here, the dye's high water solubility and lack of functional groups besides three sulfonic acids groups can lead to severe limitation in terms of leaching. Recently, we demonstrated that the coupling of pyranine with benzalkonium chloride into a water-insoluble ion pair can solve this problem for a range of $\mathrm{pH}$ values. ${ }^{[27]}$ Loading of the ion pair onto a porous support allowed the fabrication of a sensor for wound $\mathrm{pH}$. Still, at higher $\mathrm{pH}$ the ion pair separates and pyranine can leach out. Therefore, a stable covalent conjugation with an adequate host matrix would be preferable. 
Amphiphilic polymer conetworks (APCNs) represent a class of materials with great potential as matrices for sensor applications. ${ }^{[28-31]}$ APCNs combine a hydrophilic and a hydrophobic polymer in one network with a nanophase-separated morphology. The synergistic combination of both polymers and the unique structural features of APCNs result in a set of favorable properties that includes, amongst others, optical transparency, mechanical stability and amphiphilic swelling, resulting in permeability to aqueous solutes and compounds dissolved in organic solvents. Moreover, APCN can be permeable simultaneously for aqueous solutes and for hydrophobic gases, such as oxygen and carbon dioxide, with controlled gas and water permeability being of importance, for example, in different types of wound dressing applications. ${ }^{[32]}$ The phase morphology and functional properties of APCNs can be tailored to the desired applications by variation of the synergistically combined polymer components, molecular weights, and their weight fraction in the final APCN, allowing a level of control beyond hydrogels with one phase. ${ }^{[33]}$ Their functional properties have made APCNs prime candidates for biomedical applications, ranging from soft contact lenses and immunoisolation membranes to controlled drug release, interfacial enzyme catalysis, ${ }^{[34-41]}$ and sensor applications. ${ }^{[42-49]}$ For APCN-based sensors, the hydrophobic or hydrophilic phase was typically loaded with the sensing entities due to the difficulty of APCN functionalization. The ability to selectively load either or both phases with hydrophilic or hydrophobic compounds, respectively, for example drugs or sensing entities, offers access to even more complex functional materials. Recently, we have presented a new method for the fabrication of active ester-based APCNs that can be covalently functionalized in a controlled and convenient manner with a large variety of different entities. ${ }^{[50]}$ In this work, we exploit this active ester functionalization route to prepare a fluorescent ratiometric $\mathrm{pH}$ sensor based on an APCN matrix with covalently attached pyranine (PyrAPCN) (Figure 1). In the PyrAPCNs, a poly(dimethylsiloxane) (PDMS) nanophase is combined with a water-swellable poly(hydroxyethyl acrylate (PHEA) phase that brings the 
pyranine dyes in direct contact with the aqueous environment. The PyrAPCNs were synthesized and characterized with regard to their chemical structure, their phase morphology and their $\mathrm{pH}$-dependent fluorescent properties.

The synthesis of the PyrAPCN is schematically depicted in Figure 2a. It was monitored by attenuated total reflectance (ATR) Fourier transform infrared spectroscopy (FTIR, Figure 2b, Figure S1/2) as well as fluorescence and UV-vis spectroscopy (Figure 2c, Figure S3). First, a homogeneous hydrophobic precursor membrane (preAPCN) was synthesized via photopolymerization of TMS-protected hydroxyethyl acrylate (TMS-HEA) and the hydrophobic reactive ester monomer pentafluorophenyl acrylate (PFPA) together with a PDMS macromonomer crosslinker (MA-PDMS-MA). ${ }^{[50]}$ (FTIR spectra of all components in Figure S1). The weight ratio of HEA to PDMS was 3:2 to allow for good swelling ability in water. The degree of functionalization was only $0.2 \mathrm{~mol} \%$ PFPA relative to TMS-HEA, yet the successful incorporation of PFPA was still observable by FTIR due to the strong and distinct C-F bond signal (Figure 2b). Primary amine functionality was installed into the APCNs via the reaction with diaminopropane (DAP). The successful functionalization was confirmed by the disappearance of the C-F bond signal in the FTIR spectrum (Figure S3) and by reaction with fluorescamine, a specific assay reagent for primary amines (Figure S4). For the conjugation of pyranine, its phenol group was acetyl protected and its sulfonic acids activated towards amines as sulfonyl chlorides (pyranine-Cl). Reaction with the aminemodified conetwork resulted in the formation of stable sulfonyl amide linkages. Considering that on average only one out of 500 repeating units in the hydrophilic phase is aminefunctionalized, together with the large excess of Pyranine-Cl in solution (molar ratio $>100: 1$ ), a reaction at more than one sulfonyl chloride group is highly unlikely. However, it must be noted that each of the three sulfonyl chloride groups can react, with Figure 2a presenting only one of three possible structures. Subsequent deprotection of the pyranine and remaining TMS groups and the hydrolysis of the unreacted sulfonyl chlorides into the sulfonic acids afforded 
the final PyrAPCN. Free-standing films with a thickness of $\sim 100 \mu \mathrm{m}$ as measured by optical microscopy were prepared. High selectivity of the sulfonyl chlorides for primary amines under the employed reaction conditions was confirmed in a control experiment with an APCN bearing no amine functionality (Figure S3). The color of the dry PyrAPCN was a light yellow for protonated pyranine and an orange color in case of the sodium salt of the pyranine's phenol-OH which determines the absorption and fluorescence properties of pyranine (Figure 2d). The absorbance spectra showed not only a distinct difference between the two forms but also excellent optical transparency due to the nanoscale phase domains of the APCN. Both forms showed distinct fluorescence emissions in the dry state when excited at $406 \mathrm{~nm}$ or 460 $\mathrm{nm}$ (Figure 2c), confirming that their functional character was not compromised by the covalent conjugation.

Besides the chemical nature of the polymer components, the phase morphology of APCNs is of vital importance for their functional properties. Phase separation in APCNs is restricted by the covalent links of the network structure which results in a characteristic phase morphology with domains in the nanometer range. The phase morphology was investigated by atomic force microscopy (AFM, Figure 3a/b) and small angle X-ray scattering (SAXS) (Figure 3c), two highly complementary characterization methods. In AFM phase mode images, the softer PDMS domains appear as dark areas due to the difference in energy dissipation. ${ }^{[51-52]}$ Phase mode AFM images showed clear phase separation between hydrophilic PHEA and hydrophobic PDMS domains. Percolation and continuity within the PHEA phase can be clearly observed, whereas the roughly spherical PDMS domains appear separate due to the lower PDMS content. SAXS analysis confirmed the existence of separate domains in the nanometer range with a scattering peak $\left(\mathrm{q}^{*}\right)$ from domain-domain interference. The peak position of $15.6 \mathrm{~nm}$ can be interpreted as an inter-domain spacing, which corresponds well to the distances in the AFM images: small enough to avoid visible light scattering and, thereby, provide optical transparency. Furthermore, a second order peak $2 \mathrm{q}^{*}$, more distinctly 
observable in the related Kratky plot (Figure S6), indicates a short range domain order. No long range order was found, which is typical for such covalent network structures. ${ }^{[50]}$ Overall, the phase morphology of the PyrAPCN appeared comparable to similar APCNs, ${ }^{[50]}$ indicating little influence of the small amount of incorporated pyranine dye.

A defining characteristic of APCNs is their ability to swell in both hydrophilic and hydrophobic solvents due to their amphiphilic nature, with the swelling controlled by the overall composition. We determined the volumetric degree of swelling $S_{\mathrm{Vol}}$ for water and $n$ heptane and found swelling properties with $S_{V o l}=1.30 \pm 0.03$ in $n$-heptane and with $S_{V o l}=$ $1.40 \pm 0.02$ in water. The ability to swell in water is most important for $\mathrm{pH}$ sensors, however, in addition to changing the mechanical properties, crosslinking and swelling of the hydrophilic phase, a PDMS phase provides higher oxygen permeability that can be of importance for biomedical applications, such as wound dressings. ${ }^{[34,53-54]}$ The control over an APCNs phase morphology generally allows to drastically improve the oxygen permeability by increasing the PDMS content to achieve co-continuity. ${ }^{[34]}$

The PyrAPCN membranes were investigated as sensors for the ratiometric detection of $\mathrm{pH}$ by immersing them into different buffer solutions with $\mathrm{pH}$ values ranging from 5 to 9 and measuring the fluorescence emission after 1 min of equilibration. The emission spectra for the excitation at $406 \mathrm{~nm} 460 \mathrm{~nm}$ are shown in Figure 5a/b with the clear change in peak absorption between different $\mathrm{pH}$ values. Peak emission for excitation at $406 \mathrm{~nm}$ increases for increasing $\mathrm{pH}$ values, whereas it is reduced for excitation at $460 \mathrm{~nm}$. For a complete picture of the excitation-dependent emission properties of the membrane, a 2D excitation-emission spectrum over the excitation range from 375 to $500 \mathrm{~nm}$ is shown for $\mathrm{pH} 7$ in Figure 5c. The ratio between the intensity of emission at $537 \mathrm{~nm}$ after excitation at $406 \mathrm{~nm}\left(\mathrm{I}_{406}\right)$ and after excitation at $460 \mathrm{~nm}\left(\mathrm{I}_{460}\right)$ was plotted against the corresponding $\mathrm{pH}$ value (Figure $5 \mathrm{~d}$ ) and the data points could be fitted using a sigmoidal function (further information and fit parameters in Figure S8), demonstrating the ability of the pyranine-labeled APCN membranes to 
discriminate between different $\mathrm{pH}$ values with a 58 -fold increase in the ratiometric response from $\mathrm{pH} 5$ to 9. Plotting the same data in logarithmic scale allows the linearization of the calibration in the range from $\mathrm{pH} 5-8$. This strong response represents a substantial improvement compared to our previous work (6-fold increase from $\mathrm{pH}$ 5.5-8.5). The $\mathrm{pH}$ dependent emission properties of the pyranine-labeled APCN membranes can also be distinguished by the naked eye, when illuminated with a white light source (Figure $5 \mathrm{~d}$ ). It is of interest to note that the emission maximum at $537 \mathrm{~nm}$ observed for the pyraninelabeled APCN membranes is red-shifted by $20 \mathrm{~nm}$ compared to the fluorescence of free pyranine in aqueous solutions, which is usually centered at around $514 \mathrm{~nm} .{ }^{21}$ The fluorescent properties of pyranine and of its sulfo-derivatives are known to be solvent-dependent (solvatochromic) and sensitive to changes in the physico-chemical environment, thus the observed shift could be explained by a combination of factors including molecular modification (formation of sulfonamide moieties) and interactions with the local membrane environment. $^{[7,55]}$

The reversibility and, thus, reusability of the PyrAPCN was assessed by performing a full second calibration for one sample as well as a cycling experiment between $\mathrm{pH} 6$ and 8

(Figure S7). Both showed reversibility though a longer response time from basic to acidic $\mathrm{pH}$ values was necessary with equilibration after $\sim 30 \mathrm{~min}$. Importantly, no leaching of the fluorophore could be observed even after prolonged immersion in buffer solution due to the stable sulfonyl amide conjugation. The PyrAPCN showed excellent shelf-life stability with no sign of loss of functionality after more than one year of storage (dried state, dark), after which time some of the experiments reported in here were conducted (for example, Figure S8). In conclusion, despite pyranine's potential for fluorescent ratiometric $\mathrm{pH}$ sensors, in particular its low price, high photostability and range of $\mathrm{pH}$ sensitivity, it has been held back by the lack of adequate matrices that provide a stable covalent attachment and impede leaching. APCNs provide an excellent matrix that is thin, stable and optically transparent. The active ester- 
based conjugation approach provides a fast and convenient pathway towards a controlled and homogeneous pyranine functionalization based on highly stable sulfonamide linkages. It should be noted that the presented fabrication method is not limited to just pyranine but can be readily expanded towards other amine-reactive sensor dyes and other functional compounds, thereby, laying the foundation for a range of new sensor applications and other functional APCNs. Few dyes, however compare to pyranine's combination of favorable properties. By controlling the composition and phase morphology of PDMS-based APCNs, their swelling ability and permeability to solutes and oxygen can be controlled and tuned. This will allow to further optimize this ratiometric $\mathrm{pH}$ sensor for biomedical applications, in particular for applications in chronic wound monitoring.

\section{Supporting Information}

Supporting Information is available from the Wiley Online Library or from the author.

\section{Acknowledgements}

This work was supported by the Swiss National Science Foundation (SNSF) through the projects PP00P2_144697, PP00P2_172927, and 200021_172609 (“Teleflow”). We thank Anjani Maurya, Alexander Morel and Dr. Amin Sadeghpour for help with SAXS measurements, and Chieh-Szu Huang (all Empa) for the 2-D fluorescence spectroscopy measurements. We thank Lea Oberhänsli (Empa) for her support. We thank Dr. Daniel Rentsch (Empa) for the NMR measurements. The NMR hardware was partially granted by the SNSF (grant no. 206021_150638/1).

Received: ((will be filled in by the editorial staff))

Revised: ((will be filled in by the editorial staff)) Published online: ((will be filled in by the editorial staff)) 
References

[1] C. McDonagh, C. S. Burke, B. D. MacCraith, Chem. Rev. 2008, 108, 400-422.

[2] J. Han, K. Burgess, Chem. Rev. 2010, 110, 2709-2728.

[3] D. Wencel, T. Abel, C. McDonagh, Anal. Chem. 2014, 86, 15-29.

[4] E. Tietze, O. Bayer, Justus Liebigs Ann. Chem. 1939, 540, 189-210.

[5] O. S. Wolfbeis, E. Fürlinger, H. Kroneis, H. Marsoner, Fresenius' Z. Anal. Chem. $1983,314,119-124$.

[6] I. D. Johnson, Molecular Probes Handbook: A Guide to Fluorescent Probes and Labeling Technologies, 11 ed., Life Technologies Corporation, Carlsbad, California, 2010.

[7] C. Spies, S. Shomer, B. Finkler, D. Pines, E. Pines, G. Jung, D. Huppert, PCCP 2014, $16,9104-9114$.

[8] Z. Zhujun, W. R. Seitz, Anal. Chim. Acta 1984, 160, 47-55.

[9] N. Amdursky, PCCP 2015, 17, 32023-32032.

[10] D. B. Spry, A. Goun, M. D. Fayer, J. Phys. Chem. A 2007, 111, 230-237.

[11] G. Váró, L. S. Brown, R. Needleman, J. K. Lanyi, Biochemistry 1996, 35, 6604-6611.

[12] R. Simón-Vázquez, T. Lazarova, A. Perálvarez-Marín, J.-L. Bourdelande, E. Padrós, Angew. Chem. Int. Ed. 2009, 48, 8523-8525.

[13] T. Saha, A. Sengupta, P. Hazra, P. Talukdar, Photochem. Photobiol. Sci. 2014, 13, $1427-1433$.

[14] R. N. Dansby-Sparks, J. Jin, S. J. Mechery, U. Sampathkumaran, T. W. Owen, B. D. Yu, K. Goswami, K. Hong, J. Grant, Z.-L. Xue, Anal. Chem. 2010, 82, 593-600.

[15] T. Werner, I. Klimant, O. S. Wolfbeis, Analyst 1995, 120, 1627-1631.

[16] A. S. Kocincova, S. M. Borisov, C. Krause, O. S. Wolfbeis, Anal. Chem. 2007, 79, 8486-8493.

[17] D. A. Jankowska, M. B. Bannwarth, C. Schulenburg, G. Faccio, K. Maniura-Weber, R. M. Rossi, L. Scherer, M. Richter, L. F. Boesel, Biosens. Bioelectron. 2017, 87, 312-319. 
[18] G. J. Mohr, Sens. Actuators, B 2018, 275, 439-445.

[19] H. Offenbacher, O. S. Wolfbeis, E. Fürlinger, Sensors and Actuators 1986, 9, 73-84.

[20] S. G. Schulman, C. Shangxian, F. Bai, M. J. P. Leiner, L. Weis, O. S. Wolfbeis, Anal. Chim. Acta 1995, 304, 165-170.

[21] S. Gamsey, J. T. Suri, R. A. Wessling, B. Singaram, Langmuir 2006, 22, 9067-9074.

[22] J. T. Suri, D. B. Cordes, F. E. Cappuccio, R. A. Wessling, B. Singaram, Angew. Chem. Int. Ed. 2003, 42, 5857-5859.

[23] H. R. Kermis, Y. Kostov, P. Harms, G. Rao, Biotechnol. Progr. 2002, 18, 1047-1053.

[24] A. J. Amali, S. Singh, N. Rangaraj, D. Patra, R. K. Rana, Chem. Commun. 2012, 48, 856-858.

[25] D. A. Nivens, M. V. Schiza, S. M. Angel, Talanta 2002, 58, 543-550.

[26] A. Hakonen, S. Hulth, Anal. Chim. Acta 2008, 606, 63-71.

[27] G. Panzarasa, A. Osypova, C. Toncelli, M. T. Buhmann, M. Rottmar, Q. Ren, K.

Maniura-Weber, R. M. Rossi, L. F. Boesel, Sens. Actuators, B 2017, 249, 156-160.

[28] G. Erdodi, J. P. Kennedy, Prog. Polym. Sci. 2006, 31, 1-18.

[29] B. Iván, J. Feldthusen, A. H. E. Müller, Macromol. Symp. 1996, 102, 81-90.

[30] C. S. Patrickios, T. K. Georgiou, Curr. Opin. Colloid Interface Sci. 2003, 8, 76-85.

[31] N. Bruns, J. Scherble, L. Hartmann, R. Thomann, B. Iván, R. Mülhaupt, J. C. Tiller, Macromolecules 2005, 38, 2431-2438.

[32] S. Dhivya, V. V. Padma, E. Santhini, BioMedicine 2015, 5, 22-22.

[33] M. Rother, J. Barmettler, A. Reichmuth, J. V. Araujo, C. Rytka, O. Glaied, U. Pieles, N. Bruns, Adv. Mater. 2015, 27, 6620-6624.

[34] P. C. Nicolson, J. Vogt, Biomaterials 2001, 22, 3273-3283.

[35] G. Guzman, T. Nugay, I. Nugay, N. Nugay, J. Kennedy, M. Cakmak, Macromolecules 2015, 48, 6251-6262. 
[36] A. Janecska, B. Ivan, Abstracts of Papers of the American Chemical Society 1998, 216, U66-U66.

[37] G. O. Brown, C. Bergquist, P. Ferm, K. L. Wooley, J. Am. Chem. Soc. 2005, 127, 11238-11239.

[38] C. Lin, I. Gitsov, Macromolecules 2010, 43, 10017-10030.

[39] C. N. Tironi, R. Graf, I. Lieberwirth, M. Klapper, K. Mullen, ACS Macro Lett. 2015, 4, 1302-1306.

[40] K. Schöller, S. Küpfer, L. Baumann, P. M. Hoyer, D. de Courten, R. M. Rossi, A. Vetushka, M. Wolf, N. Bruns, L. J. Scherer, Adv. Funct. Mater. 2014, 24, 5194-5201.

[41] K. Scholler, C. Toncelli, J. Experton, S. Widmer, D. Rentsch, A. Vetushka, C. J. Martin, M. Heuberger, C. E. Housecroft, E. C. Constable, L. F. Boesel, L. J. Scherer, RSC Adv. 2016, 6, 97921-97930.

[42] N. Bruns, J. C. Tiller, Nano Lett. 2005, 5, 45-48.

[43] M. Hanko, N. Bruns, S. Rentmeister, J. C. Tiller, J. Heinze, Anal. Chem. 2006, 78, 6376-6383.

[44] M. Hanko, N. Bruns, J. C. Tiller, J. Heinze, Anal. Bioanal. Chem. 2006, 386, 12731283.

[45] S. Meskath, J. Heinze, G. Urban, Procedia Engineering 2011, 25, 31-34.

[46] S. Meskath, G. Urban, J. Heinze, Sens. Actuators, B 2011, 151, 327-332.

[47] S. Meskath, G. Urban, J. Heinze, Sens. Actuators, B 2013, 186, 367-373.

[48] Z.-B. Zhao, H. Li, Q.-L. Lu, Y.-L. Li, Y. Jiang, Polym. Int. 2017, 66, 566-572.

[49] G. Savin, N. Bruns, Y. Thomann, J. C. Tiller, Macromolecules 2005, 38, 7536-7539.

[50] S. Ulrich, A. Sadeghpour, R. M. Rossi, N. Bruns, L. F. Boesel, Macromolecules 2018, $51,5267-5277$.

[51] S. N. Magonov, V. Elings, M. H. Whangbo, Surf. Sci. 1997, 375, L385-L391.

[52] R. S. McLean, B. B. Sauer, Macromolecules 1997, 30, 8314-8317. 
[53] J. P. Kennedy, K. S. Rosenthal, B. Kashibhatla, Des. Monomers Polym. 2004, 7, 485-

494.

[54] T. Pivec, Z. Peršin, M. Kolar, T. Maver, A. Dobaj, A. Vesel, U. Maver, K. StanaKleinschek, Text. Res. J. 2013, 84, 96-112.

[55] C. Spies, B. Finkler, N. Acar, G. Jung, PCCP 2013, 15, 19893-19905. 


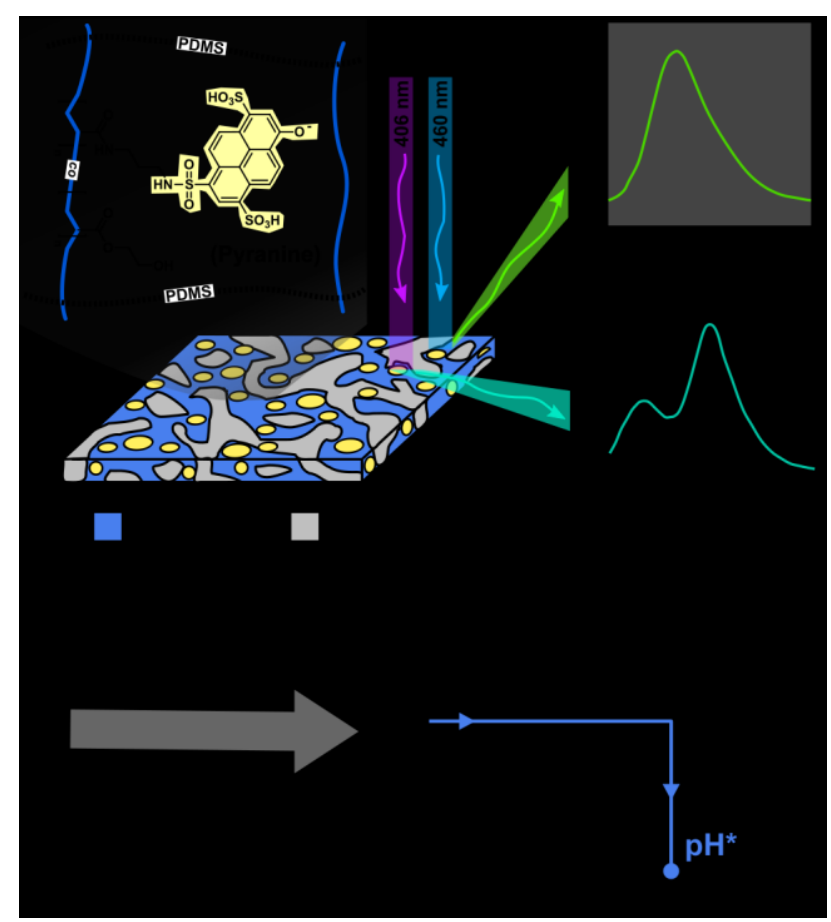

Figure 1. Ratiometric $\mathrm{pH}$ detection by nanophase-separated PyrAPCN sensors.

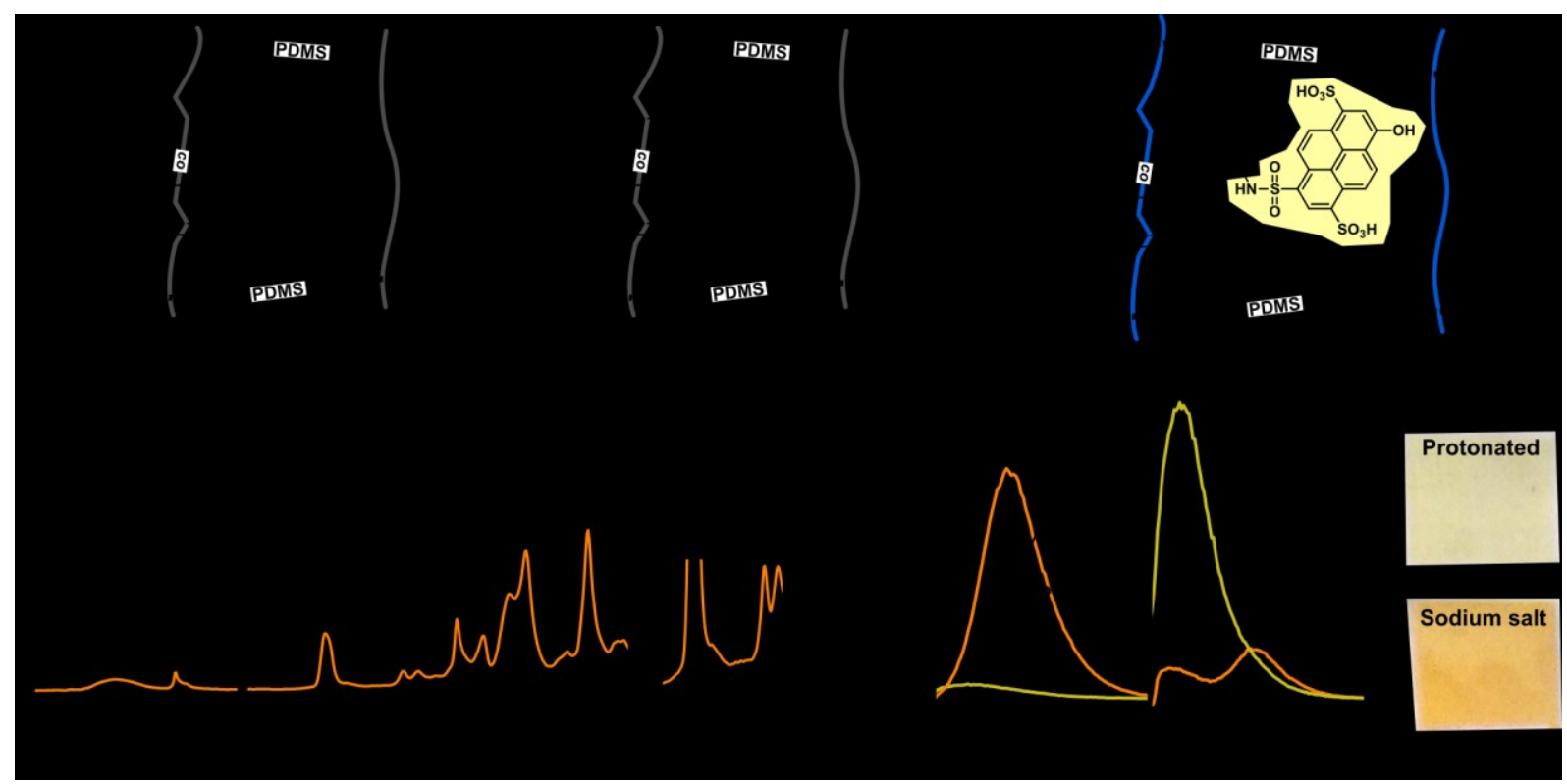

Figure 2. (a) Synthesis of PyrAPCN from active ester preAPCNs. Reaction conditions: (i) DAP/TEA; (ii) pyranine-Cl then TEA/water and deprotection of remaining TMS in acidified isopropanol/water mixture. The depicted covalently attached pyranine structure is one of three possibilities since all sulfonyl chloride groups may form the sulfonamide linkage to the network. (b) ATR-FTIR spectra of the preAPCN and the PyrAPCN. (c) Fluorescence emission spectra at $\lambda_{\mathrm{Ex}}=460 / 406 \mathrm{~nm}$ and (d) photographic images of a dry PyrAPCN with the protonated and the sodium salt form of the pyranine's phenol-OH on a white background (length $\sim 1 \mathrm{~cm}$ ). 


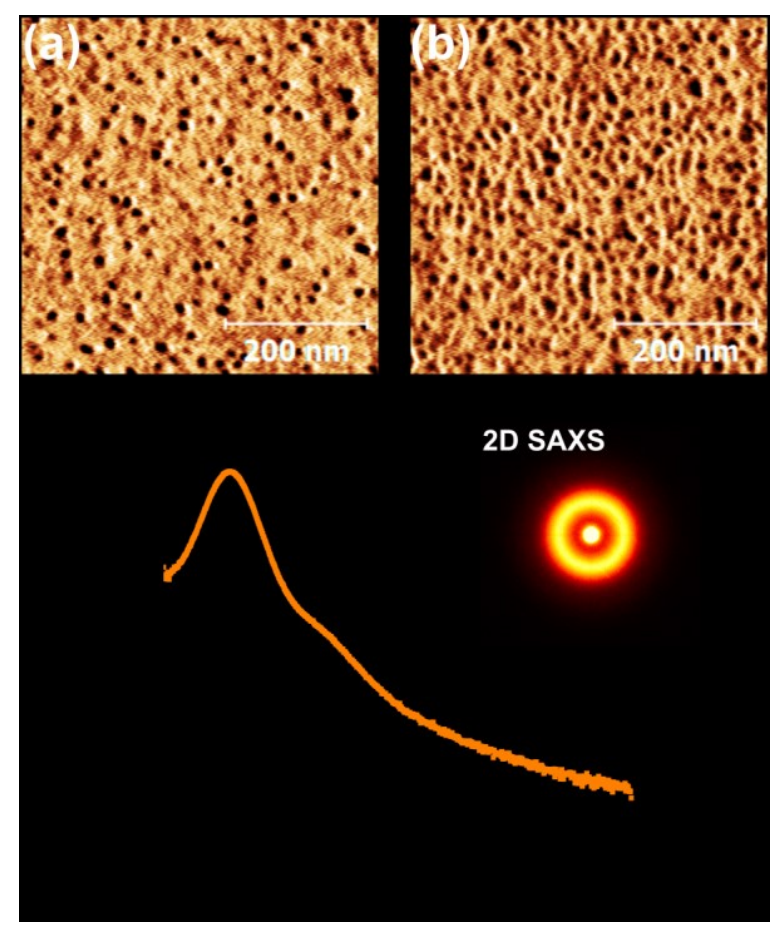

Figure 3. Phase morphology of PyrAPCN with a weight ratio PHEA/PDMS of 60:40. (a/b) Phase mode AFM images of the (surface) and a (b) cross-section. The softer PDMS domains appear dark in the phase mode images. (c) 1D SAXS trace and 2D SAXS. First ( $\left.q^{*}\right)$ and second $\left(2 \mathrm{q}^{*}\right)$ order peaks are indicated with arrows. 

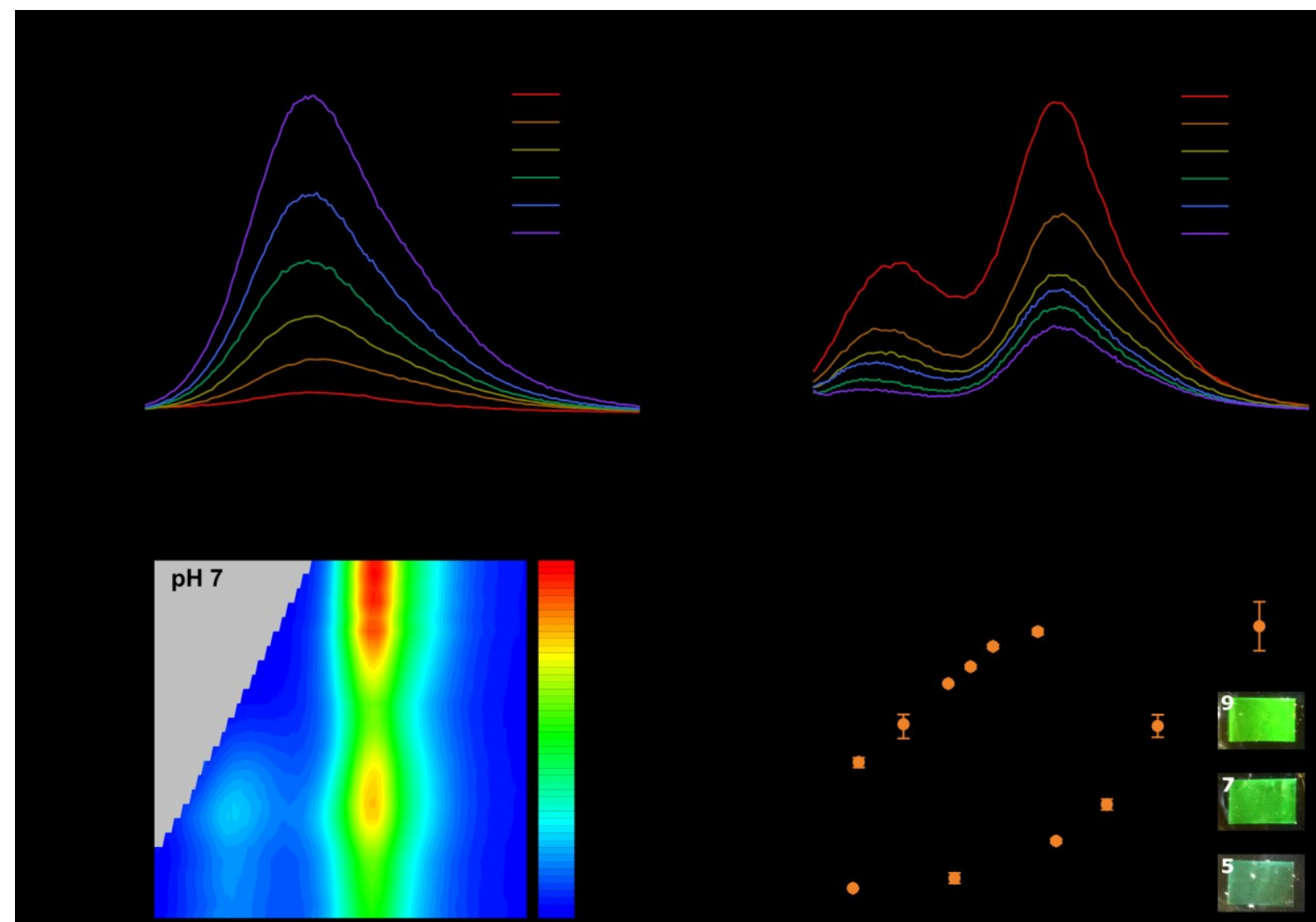

Figure 4. (a/b) Fluorescence emission spectra of the PyrAPCN after swelling in buffer solutions of different $\mathrm{pH}$ (excitation at (a) $460 \mathrm{~nm}$ or (b) $406 \mathrm{~nm}$. (c) 2-D excitation-emission fluorescence spectra of a PyrAPCN swollen at pH 7. (d) Ratiometric calibration curve obtained from peak intensities of the emission spectra at $537 \mathrm{~nm}$ (inset shows same data in logarithmic scale). Error bars represent one SD for 3 measurements. The lines represent a sigmoidal fit to the data points according to the depicted formula (fit parameters and further information in Figure S8). The photographic images show a PyrAPCN swollen at three $\mathrm{pH}$ values with white light illumination from the side. 
Pyranine is an exceptional fluorescent dye, combining high photostability with ratiometric $\mathrm{pH}$ detection in the physiological range. Nanophase-separated amphiphilic polymer conetworks provide an ideal matrix system for pyranine. An active ester-based functionalization approach ensures stable conjugation to the hydrophilic phase and contact to the aqueous environment, enabling its use as fluorescent ratiometric $\mathrm{pH}$ sensors in the range of $\mathrm{pH}$ 5-9.

Keyword Ratiometric $\mathrm{pH}$ Sensors

S. Ulrich, A. Osypova, G. Panzarasa, R. M. Rossi, N. Bruns*, and L. F. Boesel*

Pyranine-Modified Amphiphilic Polymer Conetworks as Fluorescent Ratiometric pH Sensors Title

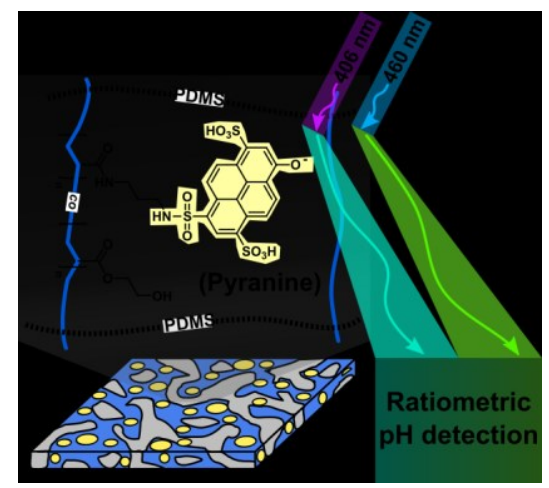


Copyright WILEY-VCH Verlag GmbH \& Co. KGaA, 69469 Weinheim, Germany, 2018.

\section{Supporting Information}

\section{Pyranine-Modified Amphiphilic Polymer Conetworks as Fluorescent Ratiometric pH Sensors Title}

Sebastian Ulrich, Alina Osypova, Guido Panzarasa, René M. Rossi, Nico Bruns*, and Luciano F. Boesel*

\section{Table of Contents}

1 Materials .2

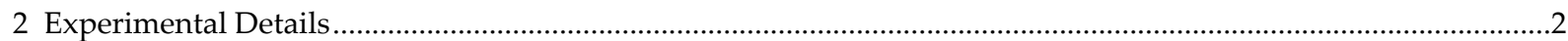

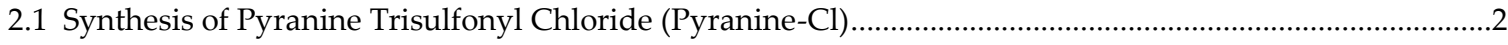

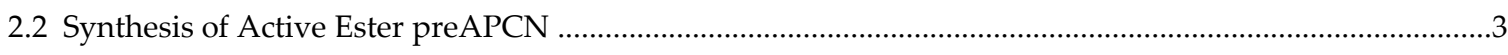

2.3 Synthesis of PyrAPCN Synthesis of Pyranine Trisulfonyl Chloride (Pyranine-Cl) ......................................

2.4 Control Experiment: Confirmation of Primary Amines in the Networks after DAP functionalization........3

2.5 Control Experiment: Selectivity of Pyranine- $\mathrm{Cl}$ for Primary Amines .........................................................4

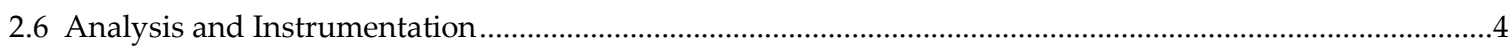

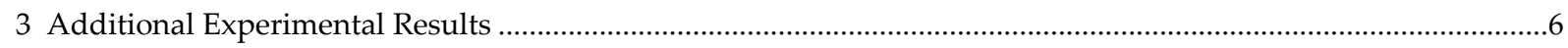

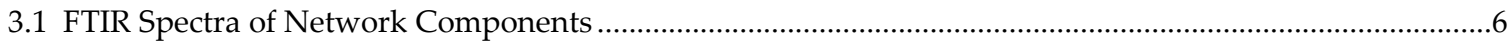

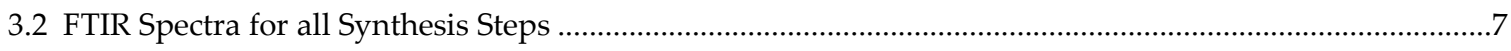

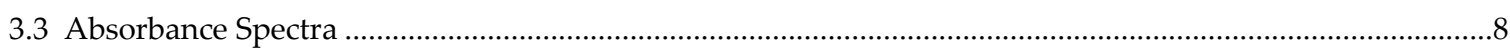

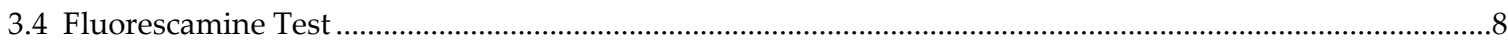

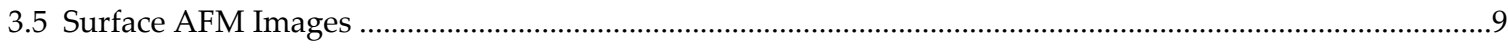

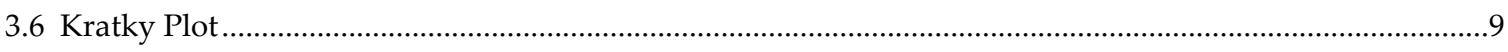

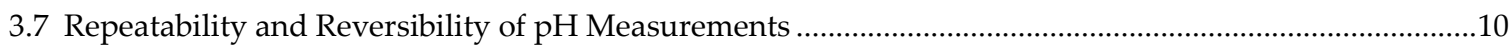

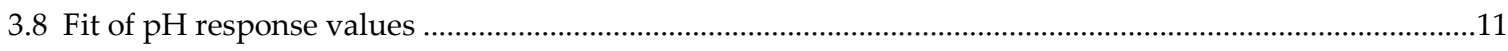

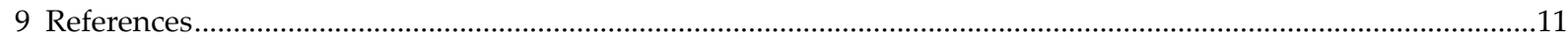




\section{Materials}

All solvents including anhydrous solvents were purchased from Sigma-Aldrich or Fisher Scientific and were of analytical or reagent grade. All chemicals not listed below were purchased from Sigma Aldrich or TCI Europe and were of analytical or reagent grade. Polypropylene tape (50 $\mu \mathrm{m}$ thickness, Tesa, Germany) was purchased from Distrelec (Switzerland). Methacryloxypropyl-terminated poly(dimethylsiloxane) (MA-PDMS-MA, viscosity 50-90 cSt, 4500-5500 $\mathrm{g} \mathrm{mol}^{-1} ;{ }^{1} \mathrm{H}$ NMR: $\mathrm{Mn}_{\mathrm{n}}=4600 \mathrm{~g}$ $\mathrm{mol}^{-1}$; GPC: $\mathrm{Mn}_{\mathrm{n}}=3500 \mathrm{~g} \mathrm{~mol}^{-1} ; \mathrm{PDI}=1.7$ with GPC and NMR characterization reported previousl $\mathrm{y}^{[1]}$ ) was purchased from ABCR (Germany). PFPA and TMS-HEA were prepared according to previously reported procedures and stored under argon at $-20^{\circ} \mathrm{C}$ until use. ${ }^{[2-3]}$ All solutions were prepared in Milli$\mathrm{Q}$ water from in-house supply unless stated otherwise. Phosphate buffer saline (PBS) solutions with a $\mathrm{pH}$ range from 5 to 9 were used to test the $\mathrm{pH}$ response. The $\mathrm{pH}$ of the buffers was adjusted with $0.1 \mathrm{M}$ $\mathrm{NaOH}$ and $0.1 \mathrm{M} \mathrm{HCl}$ using a glass electrode $\mathrm{pH}$ meter.

\section{Experimental Details}

\subsection{Synthesis of Pyranine Trisulfonyl Chloride (Pyranine-Cl)}

The synthesis was adapted from a literature procedure. ${ }^{[4]}$ First, the phenol group of the pyranine was protected with an acetyl group. $1 \mathrm{~g}(1.91 \mathrm{mmol})$ of pyranine, $10 \mathrm{~mL}$ of acetic anhydride and $16 \mathrm{mg}$ of anhydrous sodium acetate are mixed under stirring in a $25 \mathrm{~mL}$-round bottomed flask and heated to reflux $\left({ }^{\circ} \mathrm{C}\right)$ for $35 \mathrm{~h}$. Already after overnight heating, the suspension had changed from yellow to a white-grayish. After $35 \mathrm{~h}$, the mixture was allowed to cool to room temperature, then ca. $30 \mathrm{~mL}$ of THF were added and the suspension was centrifuged at $5000 \mathrm{rpm}$ for $5 \mathrm{~min}$. The pellet was redispersed in $45 \mathrm{~mL} \mathrm{THF}$, centrifuged again and redispersed in $45 \mathrm{~mL}$ of acetone, centrifuged again and put under vacuum for 3 days. The yield of acetyl-pyranine was quantitative with a creamy-white solid, insoluble in THF and acetone but very soluble in water and it was used for the next step without further purification.

For the synthesis of the tri-sulfonyl chloride, in a $25 \mathrm{~mL}-$ round bottomed flask, $1 \mathrm{~g}$ (1.93 mmol) of acetyl-pyranine was mixed together with $5.5 \mathrm{~mL}$ of thionyl chloride and $50 \mu \mathrm{L}$ of anhydrous dimethylformamide. The mixture was stirred and refluxed $\left(85^{\circ} \mathrm{C}\right)$ for $5 \mathrm{~h}$. Soon the solid dissolved forming an orange solution. After $5 \mathrm{~h}$, the solution was cooled to room temperature, then, by the aid of a pipette, it was transferred to a beaker containing ice in water. Under stirring, the orange oil rapidly turned into an orange powder. More water was added to complete the quenching and the solid was collected by filtration on a glass filter, rinsed copiously with water and dried under vacuum. The yield was $0.78 \mathrm{~g}(1.31 \mathrm{mmol}, 68 \%)$ of dry product. ${ }^{1} \mathrm{H}$ NMR $\left(400 \mathrm{MHz}, \mathrm{CDCl}_{3}\right) \delta / p p m: 9.66(\mathrm{~d}, J=9.8 \mathrm{~Hz}, 1 \mathrm{H})$, $9.61(\mathrm{~s}, 1 \mathrm{H}), 9.48(\mathrm{~d}, J=9.9 \mathrm{~Hz}, 1 \mathrm{H}), 9.44(\mathrm{~d}, J=9.6 \mathrm{~Hz}, 1 \mathrm{H}), 8.90(\mathrm{~s}, 1 \mathrm{H}), 8.82(\mathrm{~d}, J=9.7 \mathrm{~Hz}, 1 \mathrm{H}), 2.68(\mathrm{~s}$,

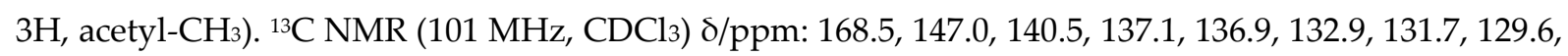
$128.0,127.9,127.3,126,3,125.9,125.3,125.1,124.4,123.1,21.0$. 


\subsection{Synthesis of Active Ester preAPCN}

The synthesis of the preAPCNs followed a modified protocol that we reported previously.[1] Photoinitiator Irgacure 651 (12 mg, $47 \mathrm{mmol})$ was dissolved in TMS-HEA (1.52 mL, $1.44 \mathrm{~g}, 7.65 \mathrm{mmol})$ in a screw cap glass vial, followed by the addition of PFPA $(2.5 \mu \mathrm{L}, 4 \mathrm{mg}, 0.015 \mathrm{mmol})$ and MA-PDMSMA $(0.6 \mathrm{~mL}, 0.59 \mathrm{~g})$. The monomer mix was vortexed for $30 \mathrm{~s}$ followed by treatment in an ultrasonication bath for $30 \mathrm{~s}$. A glass slide was equipped with spacers on two sides with a total thickness of about 100 $\mu \mathrm{m}$ (two layers of $50 \mu \mathrm{m}$ thick polypropylene tape). Monomer mixture was added between on the glass slide between the spacers and covered with a plain glass slide followed by immediate photopolymerization in a UV chamber (UVASPOT 400/T, $400 \mathrm{~W}, 315 \mathrm{~nm}$ long pass filter, Dr. Hönle AG, Germany, 3min irradiation per side). The glass slides were placed in acetone to swell the conetworks and facilitate their removal from the glass slides. The conetworks were removed and dried on a filter paper under vacuum to yield optically transparent preAPCNs of about $~ 100 \mu \mathrm{m}$ thickness. Before analysis or a functionalization reaction, the preAPCNs were washed for several hours in THF at $40{ }^{\circ} \mathrm{C}$. The thickness of the network as measured at 5 points by an optical microscope ((Keyence VHX-1000 system) was $98 \pm 3 \mu \mathrm{m}$.

\subsection{Synthesis of PyrAPCN}

The functionalization of the preAPCN with primary amines was based on a protocol that we reported previously. ${ }^{[1]}$ About $4 \mathrm{~cm}^{2}(\approx 30 \mathrm{mg}$ with $\approx 0.15 \mu \mathrm{mol}$ of active ester units) of preAPCN were placed in $10 \mathrm{~mL}$ of THF in a screw cap vial. Diaminopropane (DAP, $10 \mu \mathrm{L}, 9 \mathrm{mg}, 0.12 \mathrm{mmol}$ ) and TEA ( $5 \mu \mathrm{L}, 4 \mathrm{mg}$, $0.036 \mathrm{mmol}$ ) as an auxiliary base were added and the reaction was allowed to proceed in the closed vial on a shaker (160 rpm) at $40{ }^{\circ} \mathrm{C}$ overnight. Subsequently the conetworks were washed in THF, dried for later use (on filter paper, under vacuum) or directly used for the next step. For the reaction with the Pyranine- $\mathrm{Cl}$, a solution of Pyranine- $\mathrm{Cl}$ in anhydrous THF $\left(2 \mathrm{mg} \cdot \mathrm{mL}^{-1}, 3.3 \mu \mathrm{mol} / \mathrm{mL}^{-1}\right)$ was prepared. The conetwork were placed in $5 \mathrm{~mL}$ of the solution $(10 \mathrm{mg}, 16.5 \mu \mathrm{mol}$ of pyranine- $\mathrm{Cl},>100: 1$ ratio to amine groups) for $2 \mathrm{~min}$ followed by removal of the reactive solution and washing of the yellow pyranine-functionalized conetworks with THF to remove any unreacted pyranine. To remove the acetyl protection group and quench the unreacted sulfonyl chloride groups of the covalently attached pyranine, several drop of water and $10 \mu \mathrm{L}$ of TEA were added. The successful reaction was indicated by an immediate change of color of the conetworks due to the deprotonated phenol group. For the deprotection of the TMS groups, the conetworks were immersed overnight in a 1:1 mixture of isopropanol and water that was acidified with concentrated $\mathrm{HCl}(16$ drop/L). Subsequently, the final PyrAPCNs were washed in THF, acetone, and $\mathrm{EtOH}$, followed by drying on a filter paper under vacuum. The PyrAPCNs were stored in the dark under ambient conditions. The thickness of the network as measured at 5 points was $103 \pm 3 \mu \mathrm{m}$.

\subsection{Control Experiment: Confirmation of Primary Amines in the Networks after DAP functionalization}

To confirm the presence of free primary amine groups in the conetworks after reaction of the PFP active ester with DAP, a piece of the conetworks was immersed in a THF solution of fluorescamine in THF (20 $\left.\mathrm{mg} \cdot \mathrm{mL}^{-1}\right)$. An immediate occurrence of fluorescence only inside the conetworks but not in the solution 
was observed. The conetworks was washed in THF and acetone to remove unreacted fluorescamine and dried on a filter paper. The fluorescamine-derived fluorescence was confirmed under near UV irradiation and by fluorescence spectroscopy (Figure S4.4).

\subsection{Control Experiment: Selectivity of Pyranine-Cl for Primary Amines}

Reactivity of sulfonic chlorides for amines is much higher than for alcohol groups. ${ }^{[5]}$ Furthermore, sulfonic esters are typically not stable against hydrolysis. ${ }^{[6]}$ To investigate the selectivity of the sulfonyl chlorides of pyranine- $\mathrm{Cl}$ for primary amines, resulting in stable sulfonyl amide linkages, over the alcoholic HEA side groups, the preAPCN was treated the same as for the PyrAPCN synthesis but with $n$-butylamine instead of DAP. Thereby, no primary amines were introduced. An essentially exclusive reaction of the pyranine- $\mathrm{Cl}$ under the reaction conditions was confirmed by the absorbance spectra that show no pyranine peak and the absence of any yellow color and Figure S4.3).

\subsection{Analysis and Instrumentation}

Attenuated Total Reflectance-Fourier Transform Infrared Spectroscopy (ATR-FTIR): ATR FTIR spectra were recorded on a Varian640-IR FT-IR (Agilent Technologies) spectrometer equipped with a diamond crystal ATR unit on the sample surface with a resolution of $8 \mathrm{~cm}^{-1}$ and investigating a wavenumber range from $650 \mathrm{~cm}^{-1}$ to $4000 \mathrm{~cm}^{-1}$.

Swelling Measurements: A dry sample of about $2 \mathrm{~cm}^{2}$ was immersed into water or $\mathrm{n}$-heptane for at least one night. The edge lengths $L_{i}$ before and after swelling were measured with an optical microscope (Keyence VHX-1000 system), and the average volumetric degree of swelling $S_{\text {Vol }}$ was determined from the four sample edges (length $L$ ) as

$$
S_{\text {Vol }}=\frac{1}{n} \sum_{i=1}^{4}\left(\frac{L_{i, \text { swollen }}}{L_{i, \text { dry }}}\right)^{3}
$$

Fluorescence Spectroscopy and Absorbance Spectroscopy: Emission spectra were obtained using a Cary Eclipse fluorescence spectrophotometer (Agilent, USA; settings: $5 \mathrm{~nm}$ slit width for both excitation and emission, medium photomultiplier detector). The membrane sample was analyzed while immersed in buffer solution in an open quartz cuvette (optical path length: $1 \mathrm{~cm}$ ). For each step of the cycling experiment, the membrane was equilibrated in the buffer solution for $1.5 \mathrm{~h}$, transferred to the lid of a 96-hole well-plate with buffer, covered with a cover glass against evaporation and analyzed. Since the peak fluorescence intensity exceeded the limit of the device, the ratio was taken at $570 \mathrm{~nm}$. Dry samples were analyzed in the same way on the well-plate lid. Samples with the protonated phenol-OH of pyranine were achieved already during the TMS-deprotection under acidic conditions. The pyranine form with the sodium salt of the phenol-OH was achieved by washing for several minutes in $0.1 \mathrm{M}$ $\mathrm{NaOH}$ solution, washing with water and drying. The formation of the sodium salt was further indicated by the direct change of color and fluorescence properties. Most likely, the sulfonic acid groups were also transformed into the sodium salt form. The 2D fluorescence analysis was conducted on a FluoromaxPlus fluorescence spectrometer (Horiba Scientific, Japan). The sample was swollen in $\mathrm{pH} 7$ buffer, placed on a glass slide, covered with a cover glass against evaporation and mounted in the instrument at a $15^{\circ}$ angle between light source and detector. Fluorescence intensity was measured for excitation 
from 375-500 nm (10 nm increment) in the emission range 398-650 nm (2 nm increment) with front entrance/exit slits for excitation/emission all at $2 \mathrm{~nm}$ bandpass. A Rayleigh masking for $1^{\text {st }} / 2^{\text {nd }}$ order scattering was applied (slit width 4 ). For absorbance spectra, the samples were analyzed lying flat on the lid of a well-plate on a Cary 50 Bio UV-visible spectrophotometer with a well-plate setup (Agilent, USA).

NMR Spectroscopy: The ${ }^{1} \mathrm{H}$ NMR spectra were recorded at 400.2 on a Bruker Avance III 400 NMR spectrometerv at $297.2 \mathrm{~K}$ using the standard Bruker pulse programs and parameter sets. The ${ }^{1} \mathrm{H}$ NMR spectra were referenced internally with the residual resonances of the solvent.

Atomic Force Microscopy (AFM): AFM analysis was conducted on a scanning probe microscope FlexAFM V5 (Nanosurf AG, Switzerland) equipped with a C3000 controller and the associated software (Nanosurf C3000 Version 3.7.3.6). Measurements were performed at ambient conditions in tapping mode with a silicon AFM probe (Tap-150Al-G, BudgetSensors, Bulgaria) with a force constant of $5 \mathrm{~N}$ $\mathrm{m}-1$ and resonance frequency of $150 \mathrm{kHz}$. Images were obtained on dry samples on the sample surfaces or on cross sections obtained with a microtome-type blade. The data were analyzed using Gwyddion software (Version 2.46).

Small Angle X-Ray Spectroscopy (SAXS): SAXS studies were carried out using a Nanostar SAXS instrument (Bruker AXS GmbH, Karlsruhe, Germany). The instrument is equipped with a microfocused X-ray source (Incoatec $\mathrm{GmbH}$, Geesthacht, Germany) providing $\mathrm{Cu} \mathrm{K} \alpha$ radiation and MONTEL optics with two pinholes of $300 \mu \mathrm{m}$ to focus the X-ray beam. A VÅNTEC-2000, Xe-based gas avalanche detector was used to record the $2 \mathrm{D}$ scattering patterns. The scattering patterns of dry samples were recorded over $30 \mathrm{~min}$ of exposure time at room temperature. The scattering intensities as a function of scattering vector $(q=(4 \pi / \lambda) \sin (\theta))$ were obtained by azimuthal integration of $2 \mathrm{D}$ patterns. 


\section{Additional Experimental Results}

\subsection{FTIR Spectra of Network Components}

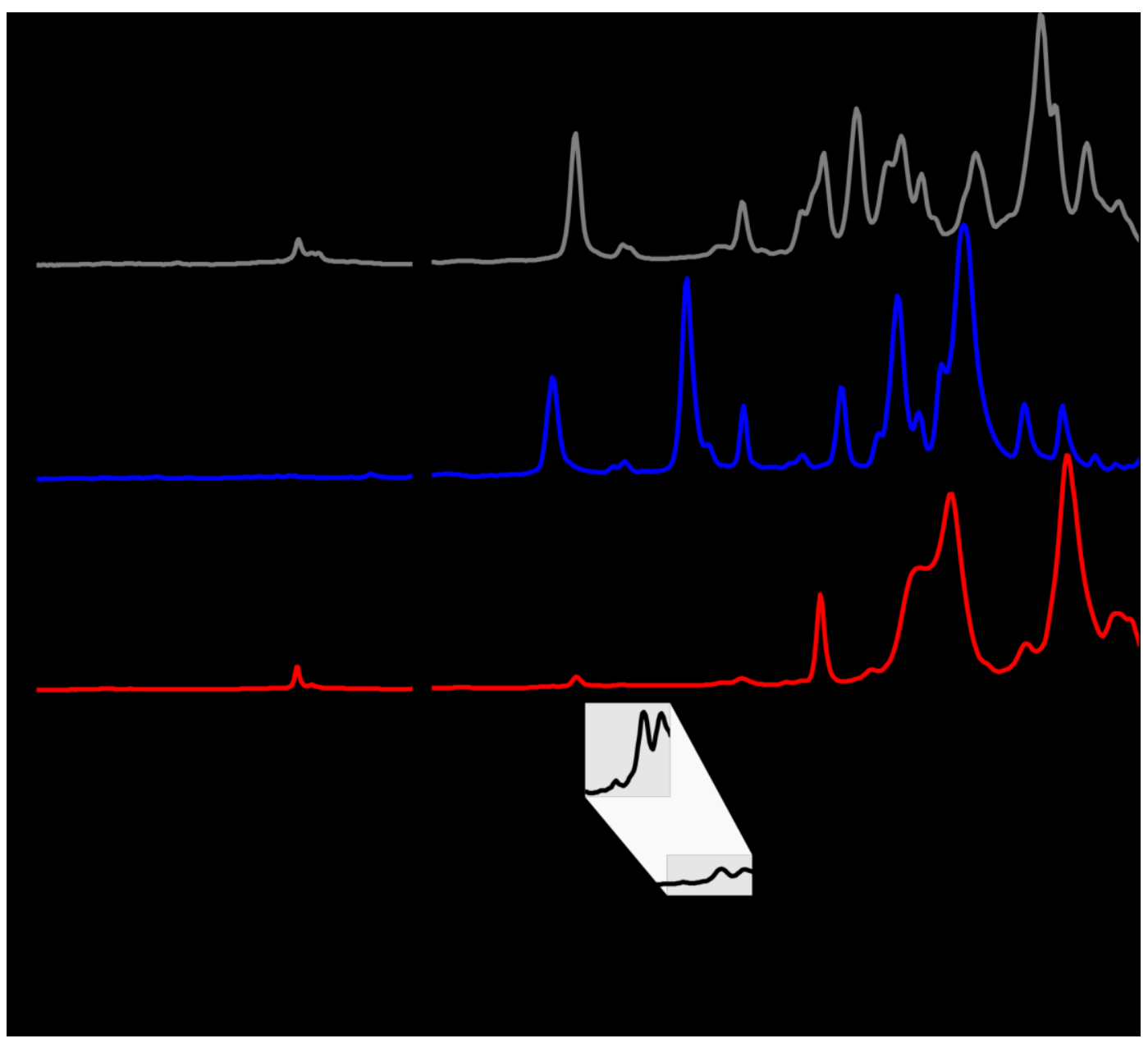

Figure S1. ATR-FTIR spectra of the monomers, the PDMS macromonomer crosslinker and the preAPCN derived from them. 


\subsection{FTIR Spectra for all Synthesis Steps}

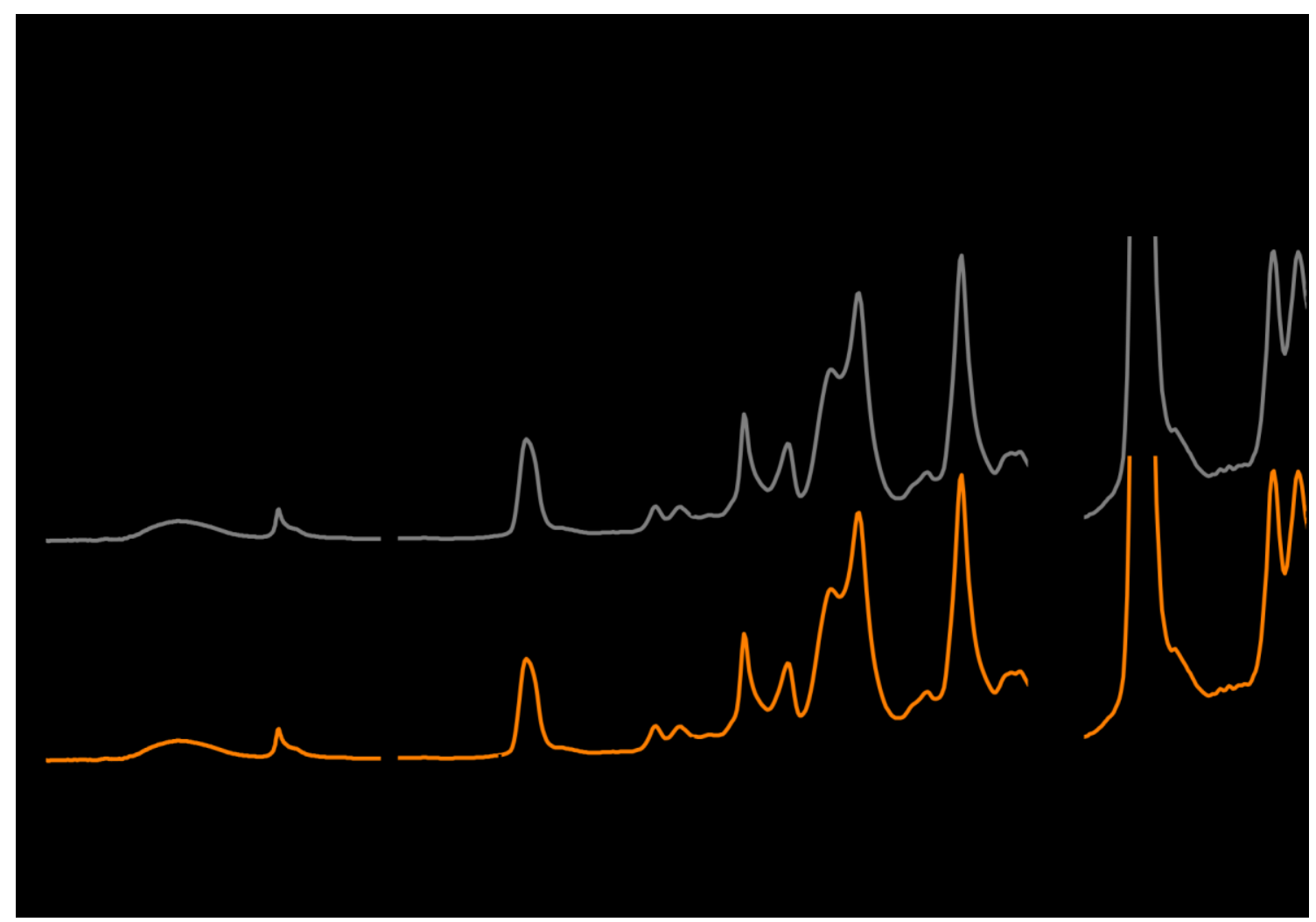

Figure S2. ATR-FTIR spectra of conetworks for all synthetic steps from preAPCN towards the PyrAPCN. 


\subsection{Absorbance Spectra}

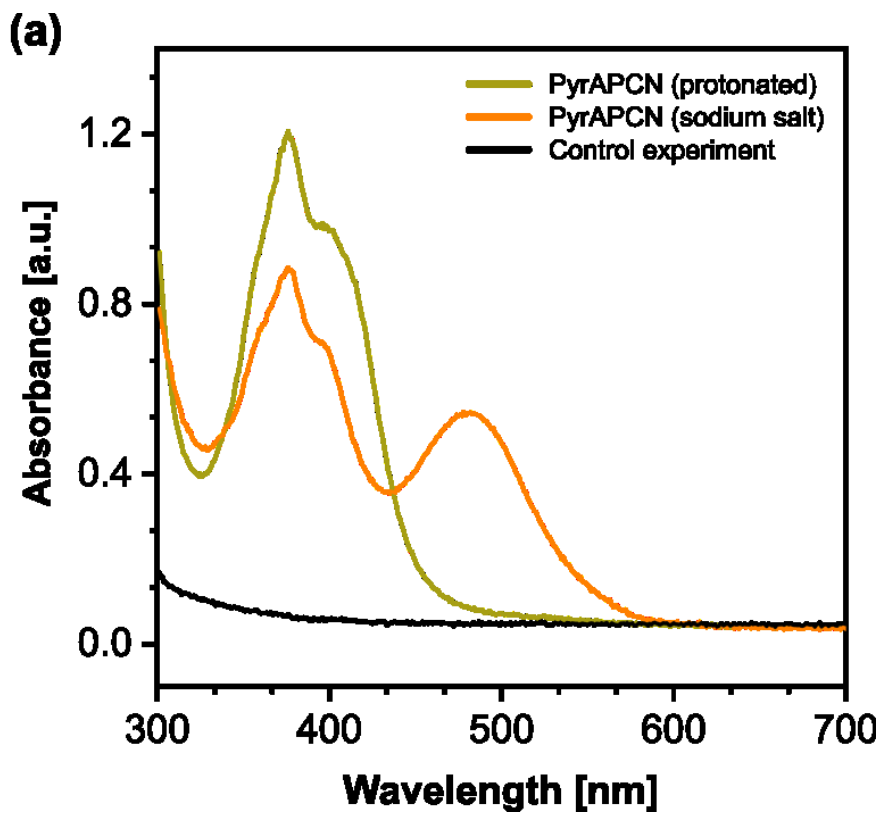

(b)

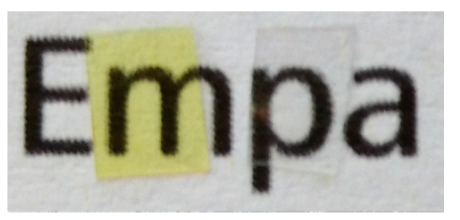

Figure S3. (a) Absorbance of the PyrAPCN in the protonated or the sodium salt form as well as the absorbance of the control APCN for which $n$-butylamine had been used instead of DAP. No pyranine absorbance is detected indicating exclusive reaction with primary amines. Notably, all APCNs show only dye-related absorbance with overall excellent optical transparency. (b) Photographic images of PyrAPCN (left) and APCN from control experiment (right). Sizes: edge length $\sim 1 \mathrm{~cm}$.

\subsection{Fluorescamine Test}
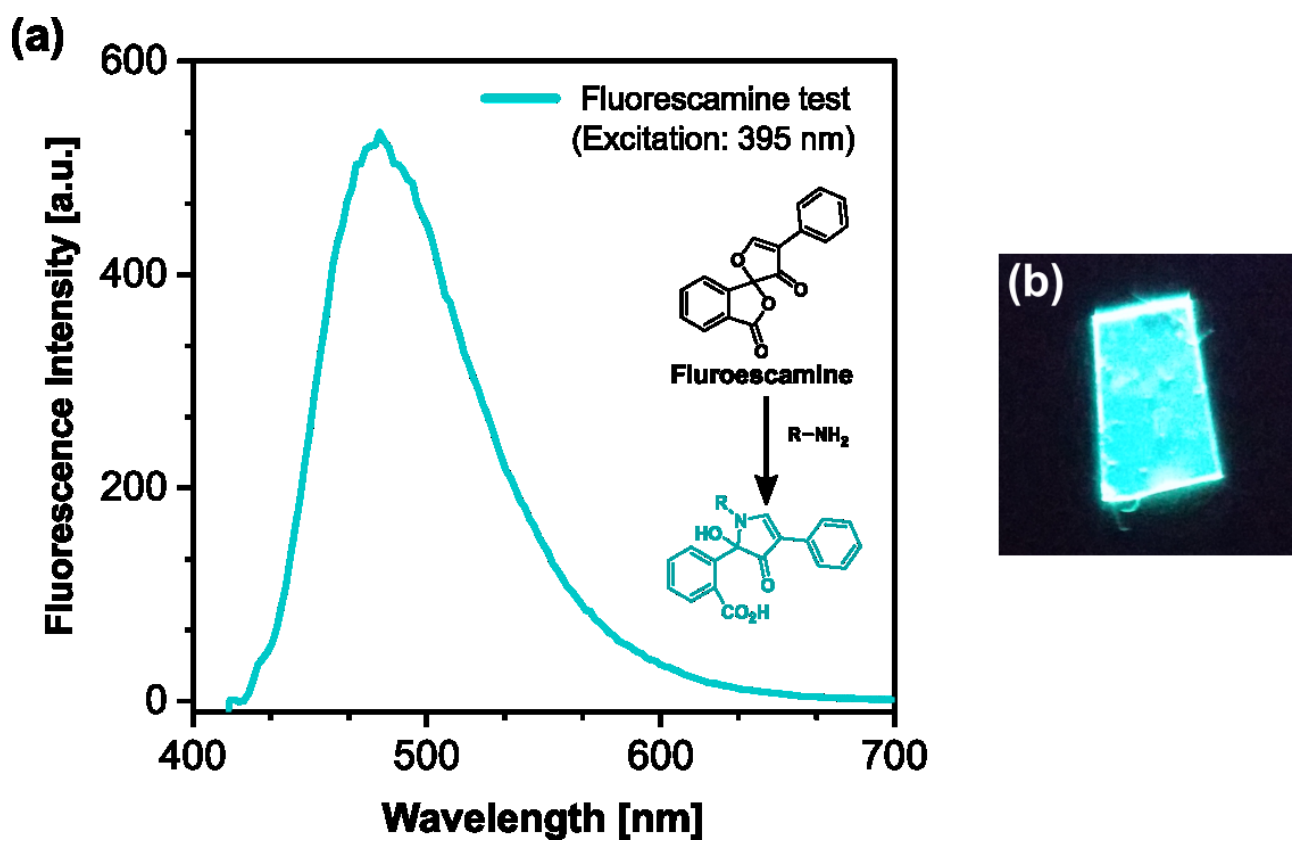

Figure S4. (a) Fluorescence of an primary amine modified preAPCN after reaction with fluorescamine and (b) photographic image of the membrane under near-UV irradiation (size: long edge $\sim 1 \mathrm{~cm}$ ). 


\subsection{Surface AFM Images}
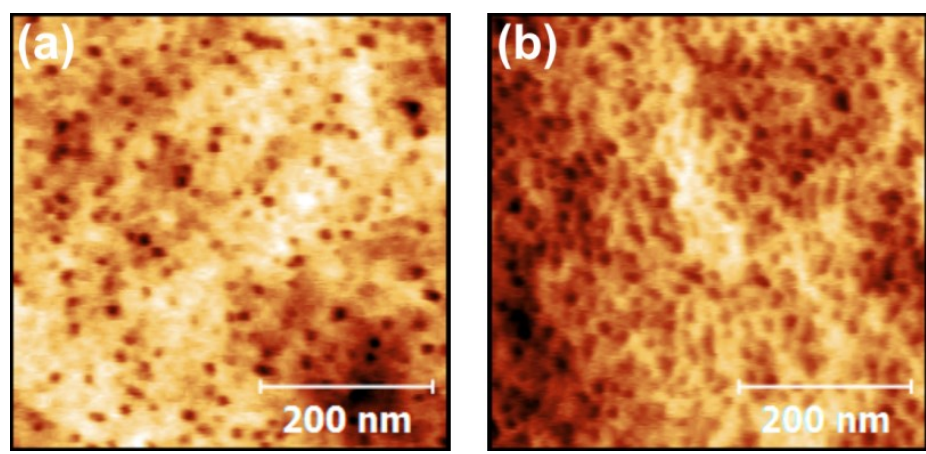

Figure S5. Height-mode AFM images of PyrAPCN of a (a) surface and a (b) cross section. The images correspond to the AFM images presented in Figure 4a/b. The phase separated domains appear in height mode images as phase artifacts.

\subsection{Kratky Plot}

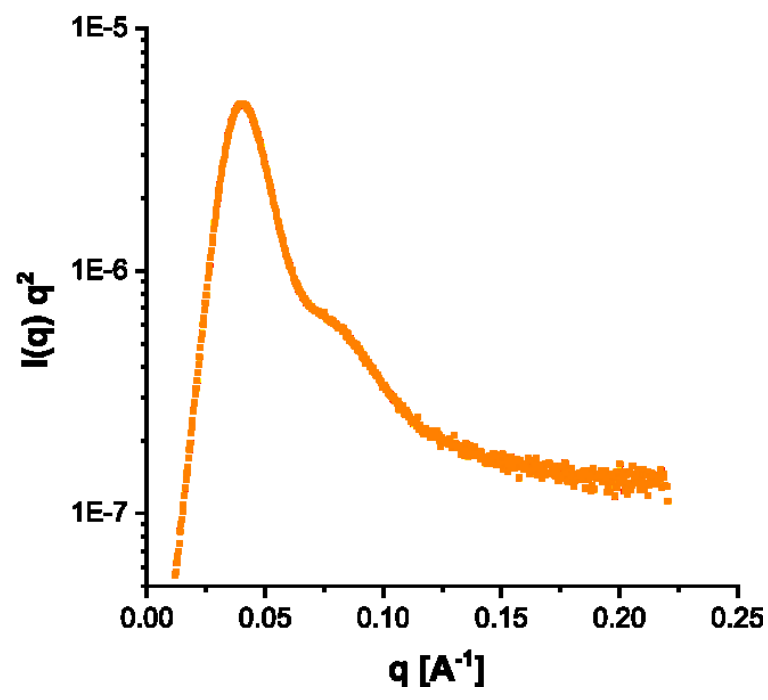

Figure S6. Kratky plot for the SAXS data presented in Figure 3 to increase the visibility of the second order peak. 

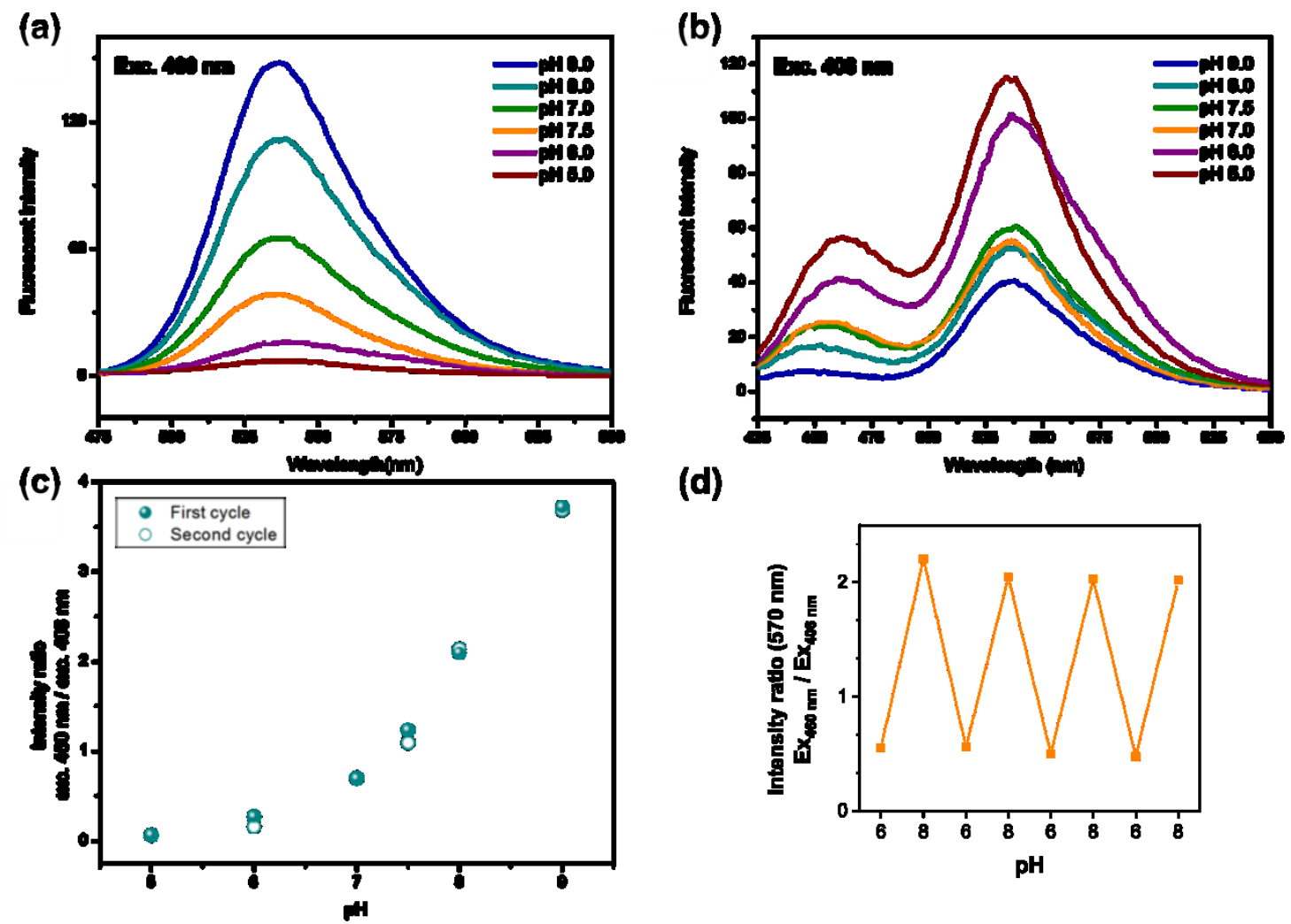

(d)

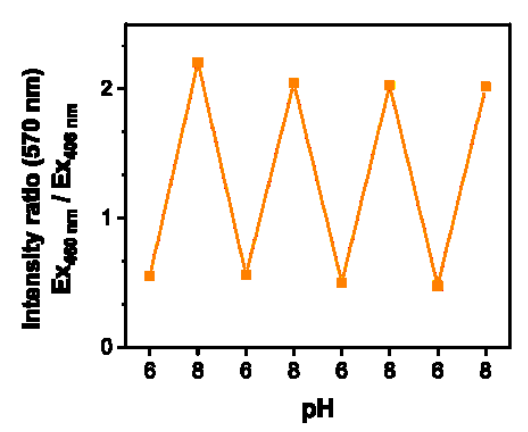

Figure S7. Reversibility of the $\mathrm{pH}$ sensing ability of the pyranine-labelled APCN membrane. After performing the cycle from $\mathrm{pH} 5$ to $\mathrm{pH} 9$ shown in Figure 3, the membrane was left overnight in $\mathrm{pH} 5$ buffer and the measurements were repeated. $(\mathrm{a} / \mathrm{b})$ Emission spectra for the excitation at $460 \mathrm{~nm}$ and $406 \mathrm{~nm}$, respectively. c) Comparison between the ratiometric response of the same membrane (537 $\mathrm{nm}$ ) after the first and second cycle of $\mathrm{pH}$ change. The points at $\mathrm{pH} 5$ and $\mathrm{pH} 7$ are overlapping. (d) Cycling experiment between two different $\mathrm{pH}$ values. The measurement was conducted on a wellplate lid where intensities were often too high. Therefore, the intensity at $570 \mathrm{~nm}$ was used. 


\subsection{Fit of $\mathrm{pH}$ response values}

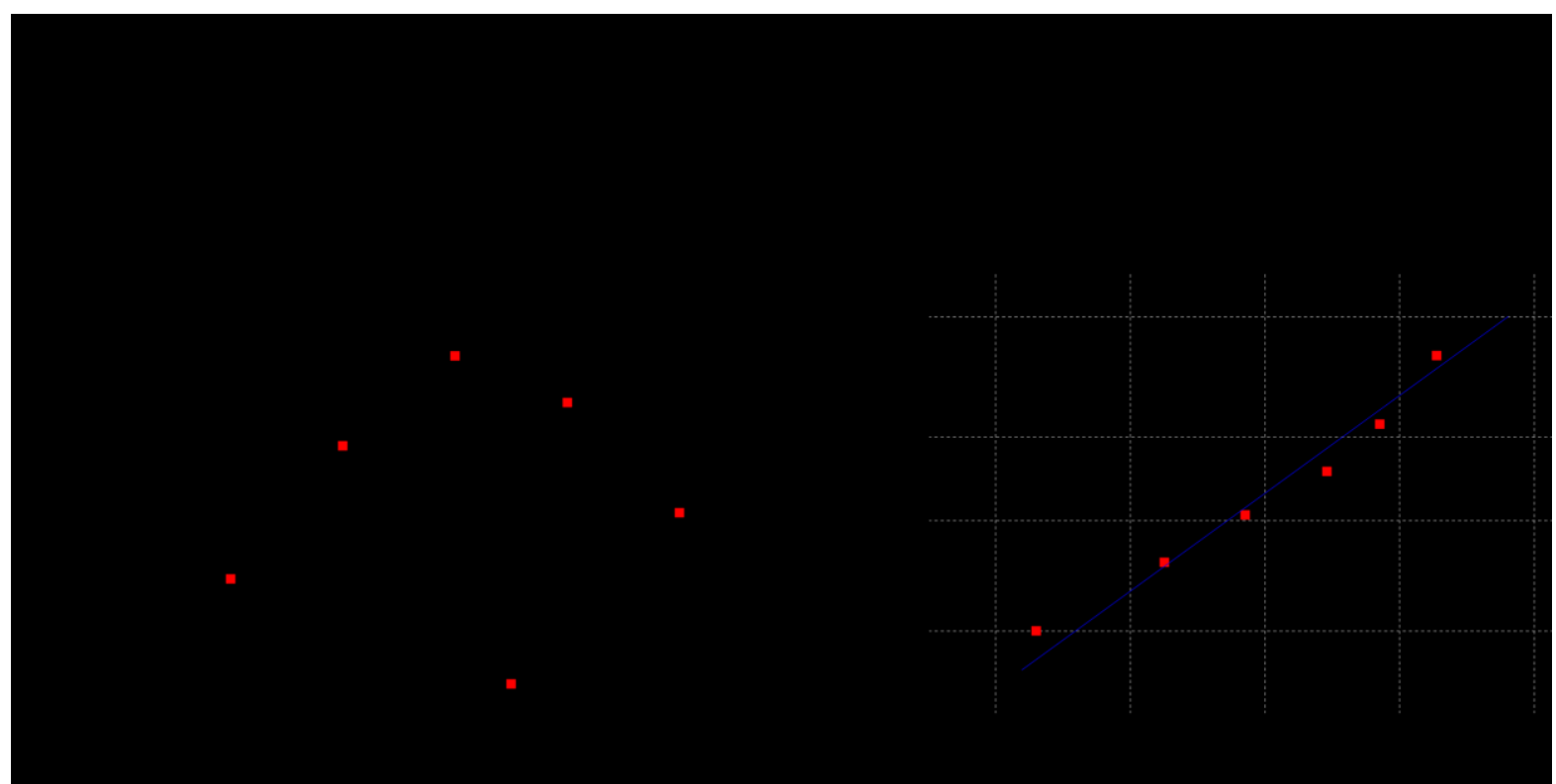

Figure S8. Data for sigmoidal fit to the $\mathrm{pH}$ response values in Figure 4.

\section{References}

[1] S. Ulrich, A. Sadeghpour, R. M. Rossi, N. Bruns, L. F. Boesel, Macromolecules 2018, 51, 5267-5277.

[2] N. Bruns, J. Scherble, L. Hartmann, R. Thomann, B. Iván, R. Mülhaupt, J. C. Tiller, Macromolecules 2005, 38, 2431-2438.

[3] F. D. Jochum, P. Théato, Polymer 2009, 50, 3079-3085.

[4] B. Finkler, C. Spies, M. Vester, F. Walte, K. Omlor, I. Riemann, M. Zimmer, F. Stracke, M. Gerhards, G. Jung, Photochem. Photobiol. Sci. 2014, 13, 548-562.

[5] I. D. Johnson, Molecular Probes Handbook: A Guide to Fluorescent Probes and Labeling Technologies, 11 ed., Life Technologies Corporation, Carlsbad, California, 2010.

[6] S. C. Miller, The Journal of organic chemistry 2010, 75, 4632-4635. 